\title{
Stenting of an outflow graft obstruction after implantation of a continuous-flow, axial-flow left ventricular assist device
}

Duc Thinh Pham, MD, Navin K. Kapur, MD, Meghan Dermody, MD, and Neil Halin, MD, Boston, Mass

See related commentary pages e13-4.

Implantation of a left ventricular assist device (LVAD) is an established treatment strategy for patients with refractory heart failure and improves both survival and quality of

From the The Cardiovascular Center, Tufts Medical Center and Tufts University School of Medicine, Boston, Mass.

Disclosure: Authors have nothing to disclose with regard to commercial support. Received for publication Feb 24, 2015; revisions received April 1, 2015; accepted for publication April 4, 2015; available ahead of print May 2, 2015.

Address for reprints: Navin K. Kapur, MD, The Cardiovascular Center, Tufts Medical

Center, 800 Washington St, Box 80, Boston, MA 02111 (E-mail: Nkapur@

tuftsmedicalcenter.org).

J Thorac Cardiovasc Surg 2015;150:e11-2

$0022-5223 / \$ 36.00$

Copyright (C) 2015 by The American Association for Thoracic Surgery

http://dx.doi.org/10.1016/j.jtcvs.2015.04.005 life. ${ }^{1-4}$ Although bleeding, infection, thromboembolism, device malfunction, right heart failure, and multisystem organ failure are known complications of LVAD implantation, the incidence of life-threatening outflow tract obstruction as a result of either device migration leading to a kink at the aortic graft anastomosis or unacceptable lie of the outflow graft is unknown. Obstructive complications from the kinking or malpositioning of an inflow or outflow cannula have previously been managed by device replacement by other investigators. ${ }^{2}$ We describe the management of an outflow graft stenosis after migration of a HeartMate II LVAD (Thoratec Corporation, Pleasanton, Calif) with balloon angioplasty and stent placement.

\section{CLINICAL SUMMARY}

A 64-year-old man with ischemic cardiomyopathy after coronary artery bypass grafting in 2004, with class IV

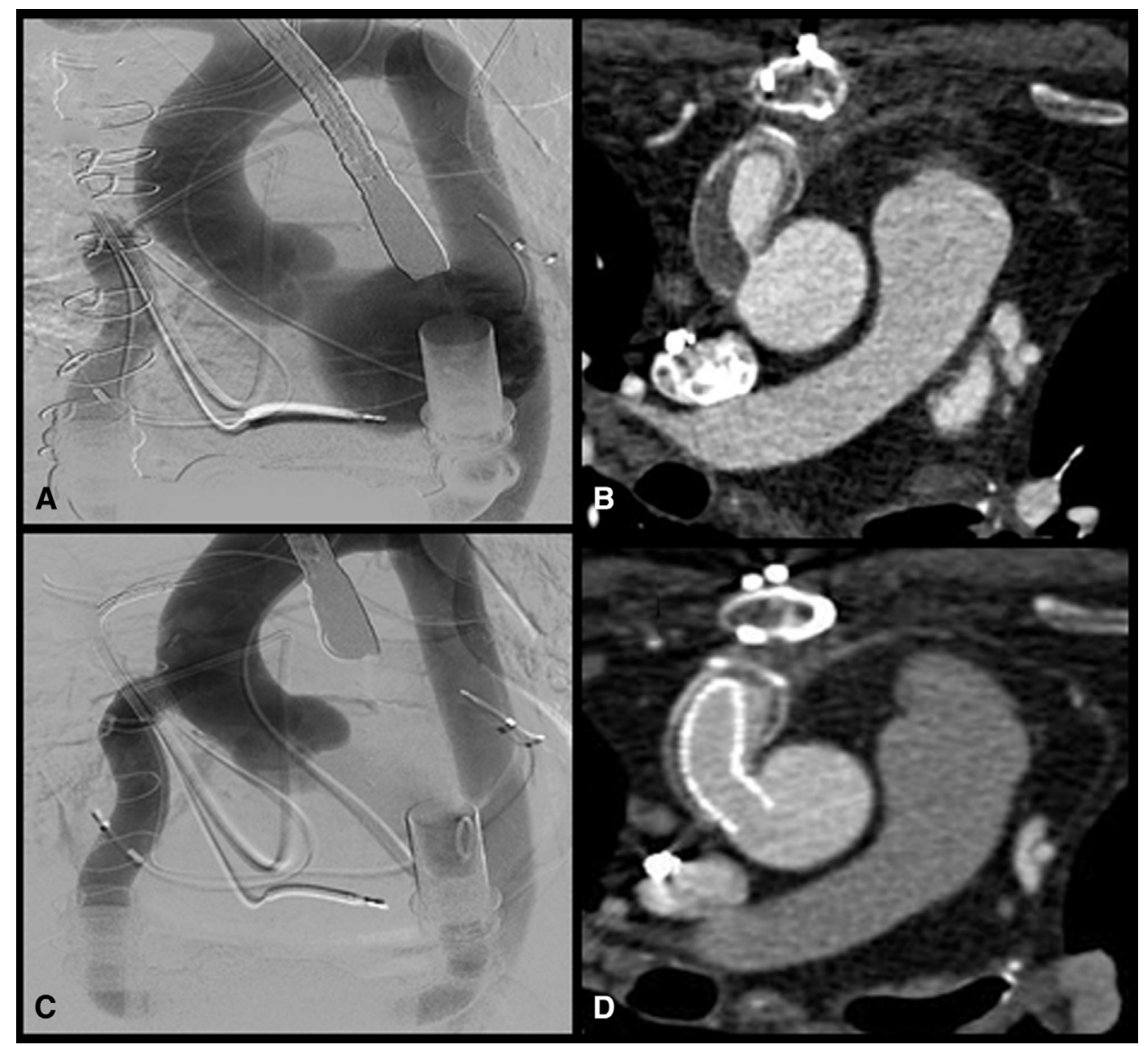

FIGURE 1. A and B, Ventriculography (A) and computed tomographic imaging (B) of the left ventricular assist device outflow graft before stenting. C and D, Ventriculography (C) and computed tomographic imaging (D) of the left ventricular assist device outflow graft after stenting. 
TABLE 1. Prestent and poststent hemodynamics and left ventricular assist device settings

\begin{tabular}{lcc}
\hline & Prestent & Poststent \\
\hline Heart rate (beats/min) & 100 & 80 \\
Systemic blood pressure (mm Hg) & $116 / 85 / 95$ & 85 (nonpulsatile) \\
Pulmonary artery pressure (mm Hg) & $47 / 28$ & $28 / 18$ \\
Central venous pressure (mm Hg) & 18 & 18 \\
Left ventricular pressure (mm Hg) & $100 / 16$ & $\mathrm{n} / \mathrm{a}$ \\
Outflow graft gradient (mm Hg) & 41 & 15 \\
LVAD speed (rpm) & 9800 & 9800 \\
LVAD flow (L/min) & 3.7 & 4.7 \\
LVAD pulsatility index & 5.1 & 2.6 \\
LVAD power (W) & 6.1 & 5.7 \\
\hline
\end{tabular}

$L V A D$, Left ventricular assist device; $n / a$; not available.

New York Heart Association heart failure underwent implantation of an axial-flow LVAD as a bridge to transplant in 2011 at another institution. One year later, he was admitted to his implanting center with heart failure, had his condition "medically optimized," and was discharged. He came to our institution with "low-flow" alarms and progressive dyspnea. On examination, he had a pulsatile blood pressure. Despite increase of the LVAD speed to 12,000 rpm, echocardiography showed dilated left ventricle with 1:1 aortic valve opening. Hemolysis laboratory values, including lactate dehydrogenase and plasma-free hemoglobin were normal. Computed tomographic angiography did not reveal inflow cannula obstruction but yielded suspicion of outflow graft stenosis, kink, or obstruction (Figure 1).

Informed consent was obtained for this high-risk endovascular procedure. The patient was taken to the hybrid operating room. After induction of general anesthesia, the patient was placed in the supine position with the left arm abducted. The chest, left arm, groins, and legs were prepared and draped. After the administration of 5000 units of unfractionated heparin, the left radial artery was accessed, and with sterile Seldinger technique, a 5F pigtail catheter was placed across the aortic valve into the left ventricle.

Initial hemodynamic parameters were obtained (Table 1), and a ventriculogram revealed predominant flow through the aortic valve and a tight stenosis of the outflow graft (Figure 1). The pigtail was pulled back into the ascending aorta and exchanged for a 0.035 -inch angled Glidewire (Terumo Medical Corporation, Somerset, NJ) and a Kumpe catheter (Cook Medical Inc, Bloomington, Ind), which were used to navigate into the outflow graft across the stenosis. Pressure measurements were obtained across the stenosis (Table 1). A $10 \times 37-\mathrm{mm}$ balloon expandable stent was then placed across the stenosis and postdilated with a 12-mm balloon. Poststent hemodynamics (Table 1) and ventriculography showed predominant flow through the LVAD. Intravascular ultrasonography across the outflow graft showed no residual stenosis. Pull-back measurements showed minimal gradient across the stent ( $41 \mathrm{~mm} \mathrm{Hg}$ prestent vs $15 \mathrm{~mm} \mathrm{Hg}$ poststent). Echocardiography showed continuous aortic valve closure and decompressed left ventricle. The patient was extubated on postprocedure day 1 . On postprocedure day 5 , a followup computed tomographic angiography was obtained and confirmed patency and good positioning of the stent (Figure 1). Six months later the patient remained free of symptoms and without evidence of LVAD dysfunction or thromboembolic events.

\section{DISCUSSION}

Obstruction of the LVAD outflow graft is a rare but potentially lethal complication with an unknown incidence. Although pump replacement has been traditionally undertaken to address this issue, it can be technically challenging and associated with a high morbidity and mortality. This is particularly true of repeated LVAD exchanges. We present the first reported case of successful percutaneous balloon angioplasty and stent placement to treat an LVAD outflow graft obstruction. Future approaches may require intravascular interrogation to rule out thrombus and the development of protection devices to limit thromboembolism during stent delivery. If thrombus is present, we would favor surgical LVAD exchange if possible. This report suggests that percutaneous diagnostic and therapeutic approaches should be considered in the management of LVAD dysfunction.

\section{References}

1. Hunt SA, Abraham WT, Chin MH, Feldman AM, Francis GS, Ganiats TG, et al; American College of Cardiology; American Heart Association Task Force on Practice Guidelines; American College of Chest Physicians; International Society for Heart and Lung Transplantation; Heart Rhythm Society. ACC/AHA 2005 guideline update for the diagnosis and management of chronic heart failure in the adult: a report of the American College of Cardiology/American Heart Association Task Force on Practice Guidelines (Writing Committee to Update the 2001 Guidelines for the Evaluation and Management of Heart Failure): developed in collaboration with the American College of Chest Physicians and the International Society for Heart and Lung Transplantation: endorsed by the Heart Rhythm Society. Circulation. 2005;112:e154-235.

2. Miller LW, Pagani FD, Russell SD, John R, Boyle AJ, Aaronson KD, et al. Use of continuous-flow device in patients awaiting heart transplantation. $N$ Engl J Med. 2007;357:885-96.

3. Slaughter MS, Rogers JG, Milano CA, Russell SD, Conte JV, Feldman D, et al. Advanced heart failure treated with continuous-flow left ventricular assist device. N Engl J Med. 2009;361:2241-51.

4. Pagani FD, Miller LW, Russell SD, Aaronson KD, John R, Boyle AJ, et al. Extended mechanical circulatory support with a continuous-flow rotary left ventricular assist device. J Am Coll Cardiol. 2009;54:312-21. 